\title{
DIÁLOGOS ENTRE O CORPO E A NATUREZA: AS PRÁTICAS CORPORAIS AO AR LIVRE E A EDUCAÇÃO FÍSICA ESCOLAR
}

\author{
DIALOGUES BETWEEN BODY AND NATURE: OUTDOOR ACTIVITIES \\ AND PHYSICAL EDUCATION
}

DIÁLOGOS ENTRE EL CUERPO Y LA NATURALEZA: LAS PRÁCTICAS
CORPORALES AL AIRE LIBRE Y LA EDUCACIÓN FÍSICA ESCOLAR

André Dalben*

Palavras chave: Educação física. História.

Corpo.

Exercício.
Resumo: 0 artigo pretende oferecer uma contribuição aos professores de Educação Física por meio de uma abordagem histórica do corpo, da natureza e das práticas corporais ao ar livre. 0 seu objetivo é analisar a história das práticas corporais ao ar livre e as relações estabelecidas ao longo do tempo com o universo escolar. A sua justificativa está atrelada à necessidade de definirmos e legitimarmos as práticas corporais ao ar livre como um conteúdo da cultura corporal passível de ser abordado pela Educação Física Escolar.

Keywords:

Physical Education. History.

Body.

Exercise.

Palabras clave: Educación Física. Historia.

Cuerpo.

Ejercicio.
Abstract: This paper intends to contribute with Physical Education teachers through a historical approach on the body, nature and outdoor physical activities. It analyzes the history of outdoor physical activities and their relations with school over time. It is justified by the need to define and legitimize outdoor physical activities as a content of body culture to be addressed by school Physical Education.

Resumen: El artículo pretende ofrecer una contribución para los profesores de Educación Física a través de un enfoque histórico del cuerpo, de la naturaleza y de las prácticas corporales al aire libre. El objetivo es de analizar la historia de las prácticas corporales al aire libre y las relaciones establecidas, a lo largo del tiempo, con el universo de la escuela. Se justifica por la necesidad de definir y legitimar las prácticas corporales al aire libre como un contenido de la cultura corporal que puede ser abordado por la Educación Física escolar.
*Universidade Estadual de Londrina (UEL). Londrina, PR, Brasil. E-mail: andredalben@yahoo.com.br

Recebido em: 28-10-2014 Aprovado em: 22-06-2015 (c) (i) () Licence 


\section{INTRODUÇÃO: O CORPO, AS PRÁTICAS CORPORAIS E A NATUREZA NA PERSPECTIVA HISTÓRICO-CULTURAL}

A Educação Física Escolar tem como principal objeto de estudo e de trabalho o corpo humano. No entanto, é indispensável notar que seu objeto não é estanque, único e imutável. Muito pelo contrário, as representações sobre o corpo são inúmeras e de diversas ordens. 0 que equivale a dizer, em última instância, que o principal objeto da Educação Física é múltiplo. Expressão poética de engenho celestial, segundo mitologias criacionistas; moradia da alma e da faísca divina, em leituras religiosas; parte integrante e indissociável da natureza e do cosmos, de acordo com a teoria hipocrática dos humores; conjunto de estruturas biológicas e de camadas de tecidos, como nos diz a anatomia; ou então, conjunto de alavancas e ações musculares, como alegado pela cinesiologia e pela biomecânica - as representações construídas para 0 corpo ao longo da história não se fazem cessar (SOARES, 2001, 2007, COURBIN; COURTINE; VIGARELLO, 2008). O corpo se configura, para além de sua materialidade biológica, como ponto de ancoragem da cultura, como "uma realidade multifacetada e, sobretudo, um objeto histórico: memória mutante das leis e dos códigos de cada cultura" (SANT'ANNA, 1995, p. 2).

De acordo com Bracht (1999), foi a partir da década de 1980 que a Educação Física brasileira começou a empregar as disciplinas das Ciências Humanas para compreender o corpo enquanto objeto que não se circunscreve unicamente ao âmbito biológico e à análise mecânica do movimento. Nesse sentido, a metodologia de ensino crítico-superadora, desenvolvida em 1992 pelo Coletivo de Autores, teve uma grande representatividade ao definir a expressão corporal como linguagem e ao empregar o conceito de cultura corporal. Apoiando-se nos estudos de Leontiev, Luria e Vigotskii (1988), os autores trouxeram para a área da Educação Física Escolar a reflexão do corpo enquanto uma realidade simbólica conformada pela linguagem. Afirmaram que o movimento que pode receber o adjetivo de humano é o movimento que tem significado, ou seja, o gesto, e não o simples ato motor (METODOLOGIA..., 1992; MATSUMOTO, 2009). De modo geral, a intenção principal dos autores, na época, fora a de se opor à perspectiva de que a Educação Física Escolar deveria trabalhar fundamentalmente com desenvolvimento da aptidão física, inserindo o debate do corpo compreendido como uma realidade simbólica (DAOLIO, 2004).

As relações entre o corpo e a linguagem podem ser compreendidas também segundo os estudos de Gleyse $(2007,2010)$. De acordo com o autor, são as palavras que dizem ao corpo o que é de bom ou de mau gosto, o que deve incitar a sua vontade ou causar o seu repúdio e asco, o que deveria considerar como limpo ou sujo, ou mesmo, como lícito ou ilícito. Foram os interditos corporais expressos pelas palavras de manuais de civilidade, como de Erasmo de Rotterdam (1466-1536), por exemplo, que produziram, segundo Norbert Elias (2011), uma aprendizagem progressiva de emoções e comportamentos aceitos e desejados segundo interesses específicos. São as palavras dos discursos, em última análise, que dizem ao corpo o que este deve vigiar e punir ou, então, desejar e estimular. É a linguagem - matéria fundamental dos discursos e em nós incorporada pelas palavras e pelos gestos - que compõe, molda e fabrica o corpo.

Para além do corpo enquanto uma realidade simbólica, a metodologia de ensino críticosuperadora produziu também uma leitura das práticas corporais a partir das Ciências Humanas ${ }^{1}$,

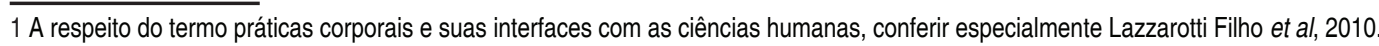


conferindo contornos mais precisos ao conceito de cultura corporal que havia começado a se delinear na década de 1980 na Educação Física brasileira (BRACHT, 1999, DAOLIO, 2004). Segundo o Coletivo de Autores (1992, p. 38), cabe à Educação Física:

[...] desenvolver uma reflexão sobre 0 acervo de formas de representação do mundo que o homem tem produzido no decorrer da história, exteriorizadas pela expressão corporal: jogos, danças, lutas, exercícios ginásticos, esporte, malabarismo, contorcionismo, mímica e outros, que podem ser identificados como formas de representação simbólica de realidades vividas pelo homem, historicamente criadas e culturalmente desenvolvidas.

Os autores tomam como referência uma abordagem histórico-cultural das práticas corporais, definindo os conteúdos da Educação Física Escolar como um acervo de práticas corporais socialmente construídas e historicamente acumuladas e que necessita ser retraçado e transmitido aos alunos na escola. Nesse sentido, partem da premissa de que a escola não desenvolve o conhecimento a ser trabalhado pelas disciplinas, mas se apropria do saber conformado pelas sociedades em diferentes épocas e lugares, conferindo um tratamento metodológico de modo a facilitar sua apreensão pelo aluno².

De acordo com o Coletivo de Autores (1992), a seleção dos conteúdos da Educação Física Escolar brasileira esteve atrelada à própria dinâmica histórica de conformação da área enquanto campo de conhecimento, tendo as diferentes práticas corporais recebido tratamento pedagógico de modo que pudessem ser ensinadas aos alunos. A ginástica, primeiro nome conferido à Educação Física, ao se distanciar do universo circense e das festas populares para se filiar à lógica militar e dos saberes médico-científicos, foi o seu primeiro conteúdo escolar (SOARES, 1998). O esporte, no caso brasileiro, começou a receber um tratamento pedagógico ainda nas primeiras décadas do século XX, alcançando, a partir da década de 1940, a hegemonia entre os conteúdos ensinados pela disciplina da Educação Física (SOARES, 1996; BRACHT, 1999). Nas duas últimas décadas, as lutas, assim como as artes circenses, antes marginalizadas, têm sido analisadas e compreendidas como indispensáveis componentes da cultura corporal, se fazendo cada vez mais presentes no ambiente escolar enquanto conteúdo de ensino da Educação Física (SILVA, 2009; BORTOLETO, 2010).

Como explicitado pelo Coletivo de Autores (1992), o caráter histórico do processo de sistematização dos conteúdos da Educação Física Escolar evidencia ser este inesgotável e provisório, ou seja, aberto a novas explorações e proposições. Compreende-se, deste modo, que, ao acervo de conteúdos acima descritos, podemos agregar outros, como as práticas corporais ao ar livre. Os banhos de mar, em rios e lagos, os passeios a cavalo, os acampamentos, a exposição do corpo ao sol, as caminhadas em bosques e parques, assim como uma diversidade de jogos e brincadeiras ao ar livre, se constituem como construções históricas que se ancoraram em uma nova visão estabelecida pelo ser humano frente à natureza. Constituem-se como práticas corporais que se encontraram vinculadas, durante 0 século XIX, ao universo da medicina natural e das vilegiaturas, sendo a natureza interpretada como um elemento curativo e prazenteiro. Partilharam, assim, de uma mesma matriz histórica, o que nos permite agrupá-las como conteúdo da Educação Física Escolar. O próprio Coletivo de Autores (1992) se reporta a essas práticas corporais ao discutir o excursionismo e admite que poderiam enriquecer as aulas de Educação Física ao problematizar questões como a ecologia.

2 A respeito dos processos de construção dos conteúdos escolares, conferir especialmente o artigo de Faria Filho et al, 2004, que traça um panorama sobre as pesquisas históricas relativas a este tema. 
Não se trata de pensarmos as inúmeras possibilidades atuais de se trabalhar esse conteúdo, mas de definirmos e legitimarmos as práticas corporais ao ar livre enquanto uma expressão da cultura corporal que foi codificada ao longo do tempo e que se encontra disponível para ser debatida, vivenciada, problematizada e ressignificada por professores e alunos nas aulas de Educação Física.

O diálogo proposto por este artigo procura extrapolar os debates que por muito tempo dominaram as Ciências Humanas, particularmente a Filosofia e a Antropologia, sobre diferenciações e oposições entre natureza e cultura. Assim como Silva (2007), considero necessário compreender a natureza como um elemento que "[...] põe em movimento um conjunto de sensações, pensamentos, imagens, lembranças, necessidades, pulsões e emoções". Procurei, deste modo, me ater em como foram construídas diversas representações para a natureza ao longo do tempo, em como os elementos naturais - como as plantas, animais, rios, mares, montanhas e tudo que pode vir a ser considerado, de maneira mais ampla, como paisagem ${ }^{3}$ - foram interpretados por diferentes discursos e narrativas para o estabelecimento de uma ideia de natureza regeneradora e benevolente.

A etimologia da palavra pode ser um interessante ponto de partida para iniciarmos essa conversa. Silva $(1999,2001)$ e Kesselring $(2000)$ analisam as transformações que o termo natureza (physis) experimentou ao longo da história ocidental, desde a Antiguidade clássica. Antes de se pautar nos cânones da ciência moderna, de ser objeto científico e de manipulação, a natureza não era um dado em si. Na Antiguidade representava o cosmos, o universo e tudo o que existe, era o princípio de cada ser singular. Já na mitologia cristã, a natureza seria concebida no âmbito da criação, pois se acreditava que nela se manifestavam a bondade e a sabedoria divina, sendo, por exemplo, a água um elemento purificador. Uma relação mística entre o ser humano e a natureza aparece, de fato, em diferentes culturas, sendo o conceito de natureza bastante plástico, uma vez que acompanhou as mudanças históricas de nossas sociedades.

Para além de sua etimologia, seria apropriado pensarmos, como nos instiga Lenoble (1969), nas diferentes "ideias de natureza" formuladas ao longo da história. A cada época, a natureza foi redescoberta por novas sensações e emoções, apropriada de diferentes formas para novos usos, constantemente reinterpretada por inúmeros discursos e por novas mentalidades. É indispensável considerar que a natureza e seus elementos são, antes de tudo, uma construção histórica.

Thomas (1988) nos narra o processo de transformação ao longo do tempo das mentalidades em relação ao mundo natural, que, de exploração incessante, começa a ser concebido como uma preocupação ecológica, incitando o amor e o desejo pela natureza. Esse percurso, no entanto, nem sempre foi tão linear, havendo uma infinidade de particularidades em decorrência de questões econômicas, políticas, sociais e culturais. Pensemos, por exemplo, como o clima e a natureza tropical foram durante o século XIX considerados pela medicina, notadamente pelas teorias climatológicas, como fatores de inadaptação dos europeus em terras sul-americanas, supostamente responsáveis por uma degeneração física e moral (CHALHOUB, 1996). Bastante presente no Brasil do início do século XX foi também a ideia construída a respeito dos sertões e do mundo rural como uma terra hostil e imprópria ao

3 A respeito do conceito de paisagem, recomenda-se a obra de Corbin (2001), na qual o autor discorre especialmente sobre a história das sensibilidades corporais em relação à natureza e seus elementos. 
desenvolvimento de uma vida considerada civilizada (LIMA, HOCHMAN, 2004). Pensemos ainda como as populações indígenas e africanas foram concebidas como mais próximas à natureza, em uma concepção de primitivismo bastante negativa e estigmatizante, que legitimou a escravidão no Brasil desde o seu período colonial (PIKE, 2001).

Podemos observar, deste modo, que as ideias de natureza construídas ao longo do tempo se fizeram múltiplas, polissêmicas, complexas. As próprias sensibilidades humanas em relação à natureza e seus elementos, como o sol, o ar livre, as águas de rios e mares, a montanha e a praia, nem sempre foram as mesmas na longa duração histórica (CORBIN, 1987, 1989, 2001). Por muito tempo a imensidão do mar e dos mais altos cumes montanhosos despertou uma série de medos e desconfianças, sendo inconcebível o desfrute destas paisagens enquanto uma experiência corporal desejável. Em oposição, uma natureza considerada como aprazível e carregada de virtudes seria entoada, ao longo dos séculos XVI e XVII, sobretudo por poetas e artistas. Seria responsável, por exemplo, pela idealização da vida no campo e em contato com a natureza como benéfica para as sociedades urbanas, de acordo com Williams (2011). Discursos que moldaram não apenas uma nova forma de conceber a natureza, mas que também legitimaram um novo trabalho sobre o corpo, refinando suas sensibilidades e emoções.

Conforme Corbin $(1987,1989,2001)$ nos incita a conceber, as práticas corporais ao ar livre instauram uma nova forma de se desfrutar a paisagem, despertando sensações poucas vezes antes apreciadas. A descoberta das possibilidades de divertimentos na natureza esteve associada com um peso cada vez maior que a cultura conquistou sobre as sensações imediatas, o que possibilitaria que o corpo entrasse em contato direto com os elementos naturais, que se imergisse por deleite no mar, que se despisse para o contato com os raios solares, que escalasse as montanhas e apreciasse 0 ar de altitude como mais fresco e revigorante. Como afirmado por Sirost (2009, p. 7), no século XIX, "A natureza se reconfigura nas mentalidades e nos usos para se tornar por essência um espaço lúdico, ao mesmo tempo terra de aventuras e dispositivo pedagógico". Nesse sentido, a codificação das práticas corporais ao ar livre que compõe a invenção desta natureza tida como um espaço lúdico faz parte, sobretudo, de uma ideia bastante singular de natureza que seria priorizada pela medicina natural e pelas vilegiaturas.

\section{DAS TERAPIAS NATURAIS ÀS VILEGIATURAS: A IDEIA DE UMA NATUREZA GENEROSA}

Numa época em que as causas de diversas doenças não eram totalmente conhecidas e sequer existiam medicamentos alopáticos para a maioria delas, como no século XIX, diferentes métodos terapêuticos foram concebidos para assegurar e promover a vida a partir da utilização dos recursos presentes na natureza, como a água de riachos e do mar, a luz solar e 0 ar de altitude. Práticas corporais ao ar livre, como os banhos, as caminhadas e a exposição do corpo ao sol foram empregadas inicialmente em estabelecimentos médicos privados, localizados em pequenos vilarejos distantes dos centros urbanos. Nessas instituições médicas, os pacientes, sobretudo membros da aristocracia e da burguesia europeia, chegavam por meio da malha ferroviária na esperança de apaziguar os sintomas das doenças que tomavam conta de seus corpos e que tanto angustiavam suas existências. Os tratamentos propostos se baseavam 
nos princípios de uma vida ao ar livre, em harmonia com a natureza e seus elementos, sendo a utilização de vestimentas leves sempre recomendada para que o corpo permanecesse a maior parte do tempo possível em contato com o ar livre, com os raios solares e as águas. 0 movimento corporal se faria de acordo com as prescrições dos terapeutas, ganhando a vida daqueles que procuravam por estes estabelecimentos novos ritmos e seus corpos e gestos novas feições. Tratava-se de um trabalho que atuava sobre o sensível, moldando o corpo a partir dos recursos de uma natureza interpretada como curativa e dadivosa (VILLARET, 2005; BAUBÉROT, 2004).

Os tratamentos desenvolvidos ao longo do século XIX, conhecidos como hidroterapia, helioterapia, climatoterapia e talassoterapia, despertariam a atenção não apenas de profissionais ligados à medicina natural, mas também de tisiologistas que procuravam por meios de assegurar a vida daqueles contagiados pelo bacilo da tuberculose. Incorporados aos sanatórios, os tratamentos da medicina natural recomendavam que as energias dos corpos convalescentes fossem poupadas e inteiramente direcionadas para supostos processos internos de cura, sendo o repouso ao ar livre uma das técnicas mais empregadas nos sanatórios (GUILLAUME, 1989). O sucesso alcançado por esses tratamentos no meio médico foi tamanho que rapidamente se consolidaram diversos vilarejos de cura, sendo os mais renomados aqueles incrustados nas cadeias montanhosas da Europa Central.

As comprovações científicas dos tratamentos propostos eram, no entanto, exíguas, o que faria com que uma parcela da sociedade médica desencorajasse seu emprego ou condenasse os seus fundamentos empíricos ${ }^{4}$. Essa oposição, contudo, não comprometeria o sucesso alcançado entre a população, pois, como observado por Dagognet (1998), apesar de não se pautarem na comprovação laboratorial, os tratamentos estavam alicerçados em um desejo de contato com a natureza de inspiração poética, de bases literárias. A vida ao ar livre se conservaria, de fato, por muito tempo, como uma "panaceia romântica", ligada tanto a um inconsciente ancestral que compreenderia os locais de altitude e o campo como uma manifestação do sublime e da fecundidade da natureza, assim como a um subconsciente poético bastante quimérico expresso pela literatura.

A exaltação da vida ao ar livre e o refinamento de novos sentimentos diante da natureza tinham, desse modo, uma tradição anterior aos sanatórios e à própria medicina natural, sendo proclamada, sobretudo, pelos escritos de pensadores como Jean-Jacques Rousseau (17121778) e pelo movimento literário do romantismo alemão, o qual teria o escritor Johann Wolfgang von Goethe (1749-1832) como um de seus principais representantes (BAUBÉROT, 2004). Segundo Villaret (2005), a popularidade que alcançaram os tratamentos da medicina natural no século XIX se explica também pelo fato de terem alterado as representações da água, do ar de altitude e da luz solar enquanto elementos salvadores, atualizando todo um imaginário da natureza enquanto fonte de vitalidade e de renascimento. Em muitos casos, as polarizações estabelecidas entre o meio natural e os centros urbanos mais insalubres auxiliariam também nesta ascensão social do desejo pela natureza, principalmente quando a água corrente e cristalina de fontes e riachos, assim como o agradável aroma dos pinheiros em bosques, se opunha aos fétidos odores emanados pelos esgotos a céu aberto e pelas chaminés das indústrias (CORBIN, 1987). Aos viajantes à procura dos estabelecimentos de cura, a sensação que prevalecia era de que na montanha 0 ar era mais fresco, sendo supostamente livre de

$\overline{4 \text { A respeito dos embates }}$ históricos entre os tratamentos naturais e os tratamentos alopáticos, conferir Dalben, 2015. 
poluições e de substâncias que poderiam comprometer sua pureza. Desse modo, mesmo que os fundamentos científicos para tais afirmações pudessem ser escassos ou insuficientes para os médicos da época, a convicção de que a natureza era benfazeja e indispensável para a saúde corporal não necessitava do olhar escrutinador do microscópio para se afirmar entre a população, pois essa certeza estava fortemente enraizada numa tradição literária e cultural anterior que exaltava os benefícios e prazeres concedidos por uma vida ao ar livre.

No contexto social das classes abastadas, a ida para os estabelecimentos de cura privados localizados em vilarejos nas montanhas ou no campo representava ainda a oportunidade de se afastarem, mesmo que temporariamente, do rigor dos costumes da corte ou da austeridade de códigos morais e de civilidade impostos nos meios urbanos mais elegantes. É importante lembrar que, mesmo durante o século XIX, os corpos dos membros da aristocracia se faziam sustentados por espartilhos que lhes conferiam retidão e moldavam suas carnes e gestos por ação externa. Nos estabelecimentos terapêuticos, os pacientes teriam, no entanto, que se libertar desses aparelhos ortopédicos e das roupas mais pesadas para entrar em contato com a água, o ar livre e a luz solar. Arnold Rikli (1823-1906) um dos terapeutas mais célebres de sua época, diria: "Elegância, a praga dos spas, não há nada menor nos estabelecimentos de medicina natural, onde uma certa liberdade de movimento, ou, para melhor dizer, de se vestir é necessária" (RIKLI, 1905, p. 202). Este simples gesto, de se despir da elegância ou do sofrimento conferido pelos espartilhos e pesadas vestimentas, uma vez aprovado pelas palavras dos terapeutas, acabaria por propiciar que as viagens aos estabelecimentos de cura se transformassem em uma prática bastante procurada pelas elites em seus momentos ociosos, estabelecendo a vilegiatura, ou seja, as viagens ao encontro da natureza como uma prática bastante em voga nas últimas décadas do século XIX e início do século XX (RAUCH, 2001, BOYER, 2008).

A fuga temporária do ambiente urbano e das sociedades de corte para os estabelecimentos de medicina natural abriria, assim, a ocasião para que a natureza fosse compreendida como indispensável tanto para a saúde corporal quanto para novas práticas de divertimentos e novas sociabilidades, sendo pequenos vilarejos de cura, incrustados nas montanhas, transformados em suntuosas estâncias de vilegiatura, que comportariam um semnúmero de divertimentos, como os espetáculos musicais e bailes, sessões de jogos e partidas esportivas, gincanas e brincadeiras, caminhadas bucólicas em bosques, piqueniques, passeios náuticos em lagos ou a cavalo pelas encostas das montanhas, entre tantos outros. Tomar ar fresco, banhar-se e subir a serra tornavam-se, de fato, expressões cada vez mais recorrentes entre as famílias abastadas, revelando uma nova sensibilidade para com a natureza, a qual ultrapassava os métodos recomendados pelas terapias da medicina natural. Constituía-se uma verdadeira educação do corpo ao ar livre ${ }^{5}$, guiada pelas palavras do terapeuta e com práticas corporais e divertimentos inúmeros ofertados pelos hotéis e proprietários de grandiosas residências de campo construídas nessas estâncias para a prática da vilegiatura (RAUCH, 2001, BOYER, 2008).

A viagem para a montanha comportava, assim, a ideia de partir para renascer, seja nas esperanças depositadas pelos tuberculosos e demais convalescentes no repouso ao ar livre realizado nos jardins e varandas dos sanatórios, seja na descoberta do prazer oferecido pelos divertimentos praticados pelos vilegiadores. Entre muitos dos frequentadores dos 
estabelecimentos terapêuticos, o prazer de se divertir ao ar livre, com poucas roupas, sob os raios calorosos do sol e em meio ao ar livre, se afirmaria definitivamente como a motivação maior para realizar essas viagens. Não se trataria mais somente de curar, de tratar o sofrimento, mas de se distrair e de proporcionar o gosto pela aventura de viver ao ar livre.

\section{AS PRÁTICAS CORPORAIS AO AR LIVRE: DAS FÉRIAS ESCOLARES ÀS ESCOLAS AO AR LIVRE}

Todo esse universo dos vilarejos de cura e de vilegiaturas não passaria despercebido pelos educadores e médicos escolares, sendo diversas iniciativas postas em marcha para abarcá-lo dentro da instituição escolar no final do século XIX. Fernand Lagrange (18451909), médico francês e entusiasta do esporte, conseguiria afirmar em 1890 alguns pontos para o eclético projeto dos novos programas ginásticos das escolas primárias de seu país, com propostas que incluíam os jogos ao ar livre entre os exercícios físicos recomendados (VILLARET, 2005). O médico Aimé Riant (1827-1902) também advogaria a favor da inclusão das práticas corporais ao ar livre na instituição escolar em livro publicado em 1889. Questionaria sobre a possibilidade das escolas e colégios públicos franceses importarem para dentro de seus muros alguns dos jogos que tomavam conta das vilegiaturas da alta sociedade nos jardins de suas casas de campo ou nas estâncias de cura. De modo abrangente, pode-se conceber que seu intento era de permitir a entrada do universo das vilegiaturas, com todos os seus divertimentos próprios, no ambiente escolar. É importante ressaltar, entretanto, que a democratização das práticas corporais ao ar livre por meio da escola não era sugerida, como atualmente se procede, por serem as práticas compreendidas como construções culturais passíveis e indispensáveis de serem ofertadas à população, mas principalmente devido ao seu caráter higiênico e a sua função de fortalecer o corpo infantil. De todo modo, apesar dos esforços empreendidos pelos dois médicos franceses, as práticas corporais ao ar livre ficariam ainda por muito tempo restritas à ordem do discurso, não sendo implementadas de fato nas escolas públicas daquele final do século XIX, sendo a Educação Física Escolar francesa predominada, ainda por muito tempo, pelo ensino da ginástica científica (SOARES, 1998, VILLARET, 2005).

Impassíveis de adentrar a escola, as práticas corporais ao ar livre encontrariam outro estabelecimento para se institucionalizarem: a colônia de férias. Dirigidas principalmente às crianças matriculadas no sistema público de ensino, sobretudo àquelas mais pobres e desnutridas, as colônias de férias visavam, em seus primórdios, realizar uma viagem para a montanha, para o campo ou para o litoral durante as férias escolares. Ofereceriam uma farta alimentação e a possibilidade de que práticas corporais ao ar livre fossem realizadas com o objetivo de fortalecer o corpo infantil e, consequentemente, preveni-lo de doenças. Seus objetivos, no entanto, não eram unicamente médicos, pois as colônias de férias possibilitariam que seus participantes adquirissem uma série de conhecimentos a respeito da vida ao ar livre, ao mesmo tempo em que se entregavam a divertimentos e prazeres inúmeros. Ao inaugurarem um novo espaço para o tempo das férias escolares, as colônias propiciariam que práticas corporais antes restritas às famílias abastadas fossem ofertadas às crianças mais pobres, muitas das quais jamais haviam deixado os grandes centros urbanos e eram cotidianamente exploradas pelo trabalho infantil (DALBEN, 2009, 2014a, 2014b). 
Educadores alemães, suíços e belgas, ao tomarem como inspiração maior as colônias de férias e os resultados sobre o corpo dos estabelecimentos terapêuticos da medicina natural, proporiam não apenas a inserção das práticas corporais ao ar livre na escola por meio da Educação Física, mas a completa restruturação da instituição escolar a partir dos ditames de uma vida ao ar livre, com mudanças que iam desde seus cronogramas, procedimentos pedagógicos, mobiliário até a sua arquitetura. Implantada em bosques vizinhos às cidades ou em seus parques públicos, nasceria, na primeira década do século XX, a escola ao ar livre uma instituição que almejava modificar profundamente a escola mais tradicional. A ideia era de que, se a natureza se mostrava como um livro aberto, como afirmado por tantos educadores da época, era então necessário aprender a lê-la de modo sistematizado. Da escola era exigido que mantivesse suas portas e janelas abertas para a natureza a ser investigada pelos alunos e 0 ar livre seria considerado tão bom para os métodos de ensino e os programas escolares quanto para os pulmões, os nervos e os músculos das crianças. Em seu interior se manifestariam diversas práticas corporais ao ar livre, proporcionando aos alunos uma vida escolar bastante variada, com a presença de jogos e divertimentos na natureza, diferentes tipos de trabalhos manuais, como a jardinagem e o cultivo de hortas, aulas práticas ao ar livre em que as plantas, animais, rochas, etc. eram investigados diretamente pelos alunos, momentos para recitação, teatro, música, festas e exposições ocorridas entre os bosques dessas instituições (DALBEN, 2009, 2014b, CHÂTELET; LERCH; LUC, 2003).

Nascidas em um universo médico, das terapias naturais, as práticas corporais ao ar livre seriam apropriadas não apenas para a cura de enfermidades mas também para os divertimentos característicos das vilegiaturas realizadas pelas classes mais abastadas. Impassíveis de adentrar a instituição escolar, que na época priorizava o ensino da ginástica científica, as práticas corporais ao ar livre foram trabalhadas primeiramente pelas colônias de férias, transformando, em seguida, as próprias estruturas escolares para fundar o modelo da escola ao ar livre. A partir da década de 1950, com o maior desenvolvimento e distribuição dos medicamentos alopáticos para a cura de grande parte das enfermidades, as terapias naturais perderiam seu respaldo social e científico, sendo deslocadas para ramos da medicina alternativa, extraoficial. As colônias de férias e escolas ao ar livre, por sua vez, também perderiam, neste momento, seu principal embasamento médico-científico e começariam a ganhar outras conotações, sendo as colônias de férias compreendidas, a partir de então, como instituições recreativas ligadas principalmente ao lazer, enquanto que as escolas ao ar livre começariam a fechar suas portas em diversos países. Seus ensinamentos, no entanto, perduram sobretudo como a tentativa de promover aos estudantes o gosto pela vida ao ar livre, ou seja, de incitar o desejo por uma vida transcorrida em harmonia com a natureza e seus elementos, possibilitando não apenas que o corpo se fortalecesse mas principalmente que a natureza fosse descoberta em suas potencialidades educativas.

\section{CONCLUSÃO}

A partir da ampliação da compreensão do corpo para além de sua materialidade biológica, a Educação Física Escolar brasileira estabeleceu, na década de 1990, por meio da metodologia de ensino crítico-superadora, que os seus conteúdos escolares deveriam ser compreendidos como formas de representação simbólica historicamente construídas e culturalmente desenvolvidas. A ginástica, o esporte, a dança, o circo, os jogos e as lutas foram 
eleitos pela metodologia de ensino em questão como os conteúdos mais clássicos da Educação Física, e podem, entretanto, ser ampliados a diversas outras práticas corporais constitutivas do amplo acervo gestual codificado e acumulado pela humanidade em sua história. Ao apresentar as práticas corporais ao ar livre, conclui-se que elas são passíveis de compor o repertório de conteúdos da Educação Física Escolar, uma vez que estiveram atreladas e reunidas sob um mesmo arcabouço histórico e uma mesma dinâmica cultural. Muito embora não tenham adentrado a instituição escolar durante o século XIX, as práticas corporais ao ar livre foram apropriadas pelas colônias de férias, instituições consideradas em seus primórdios como extraescolares, tornando-se componente pedagógico definitivo com o advento das escolas ao ar livre no início do século XX. Representam, assim, um profícuo conteúdo escolar passível de ser explorado por professores e alunos nas aulas de Educação Física.

\section{REFERÊNCIAS}

BAUBÉROT, Arnaud. Histoire du naturisme: le mythe du retour à la nature. Rennes: Presses Universitaires de Rennes, 2004.

BORTOLETO, Marco Antonio Coelho. Introdução à pedagogia das atividades circenses. Jundiaí: Fontoura, 2010.

BOYER, Marc. Les villégiatures du XVle au XXle siècle: panorama du tourisme sédentaire. Colombelles: Éditions EMS, 2008.

BRACHT, Valter. A constituição das teorias pedagógicas da educação física. Caderno CEDES, Campinas, v. 19, n. 48, p. 69-88, ago. 1999.

CHALHOUB, Sidney. A cidade febril: cortiços e epidemias na corte imperial. São Paulo: Companhia das Letras, 1996.

CHÂTELET, Anne-Marie; LERCH, Dominique; LUC, Jean-Noël. L'école de plein air: une expérience pédagogique et architecturale dans l'Europe du XXè siècle. Paris: Recherches, 2003.

COLETIVO DE AUTORES. Metodologia do ensino de educação física. São Paulo: Cortez, 1992.

CORBIN, Alain. L'homme dans le paysage. Paris: Gallimard, 2001.

CORBIN, Alain. Território do vazio: a praia no imaginário ocidental. São Paulo: Companhia das Letras, 1989.

CORBIN, Alain. Saberes e odores: o olfato e o imaginário social nos séculos XVIII e XIX. São Paulo: Companhia das Letras, 1987.

CORBIN, Alain; COURTINE, Jean-Jacques; VIGARELLO, Georges (Org.). História do corpo. Petrópolis: Vozes, 2008.

DAOLIO, Jocimar. Educação física e o conceito de cultura. Campinas: Autores Associados, 2004.

DAGOGNET, François. Savoir et pouvoir en medecine. Le Plessis-Robinson: Institut Synthélabo pour le Progres de la Connaissance, 1998. 
DALBEN, André. Artes de curar: embates históricos entre as terapias naturais e os tratamentos alopáticos. In: BARROS, Renata Chrystina Bianchi de; MASINI, Lucia. (Org.). Sociedade e medicalização. Campinas: Pontes, 2015. p. 81-93.

DALBEN, André. Educação do corpo e vida ao ar livre: natureza e educação física em São Paulo (1930-1945). Dissertação (Mestrado em Educação Física) - Universidade Estadual de Campinas, Campinas, 2009. Disponível em: <http://libdigi.unicamp.br>. Acesso em: 20 out. 2014.

DALBEN, André. Mais do que energia, uma aventura do corpo: as colônias de férias escolares na América do Sul (1882-1950). 2014b. Tese (Doutorado em Educação) Universidade Estadual de Campinas, Campinas, 2014b. Disponível em: <http://libdigi.unicamp. br>. Acesso em: 20 out. 2014.

DALBEN, André. Quando a saúde e a educação partem às férias: uma abordagem histórica das colônias de férias infantis no último terço do século XIX. In: BARROS, Renata Chrystina Bianchi de; PAULINO-PEREIRA, Fernando César; OLIVEIRA, Jáima Pinheiro. (Org.). Educação e saúde: questões práticas sobre o processo de integração e inclusão social. Jundiaí: Paco, 2014a. v. 2, p. 43-58.

ELIAS, Norbert. 0 processo civilizador. Rio de Janeiro: Jorge Zahar, 2011.

FARIA FILHO, Luciano Mendes et al. A cultura escolar como categoria de análise e como campo de investigação na história da educação brasileira. Educação e Pesquisa, São Paulo, v. 30, n. 1, p. 139-159, jan./abr. 2004.

GLEYSE, Jacques. A carne e o verbo. In: SOARES, Carmen Lúcia (Org.). Pesquisa sobre o corpo: ciências humanas e educação. Campinas: Autores Associados, 2007. p. 1-21.

GLEYSE, Jacques. Le verbe et la chair: un siècle de bréviaires de la République. Paris: L'Harmattan, 2010.

GUILLAUME, Pierre. Du désespoir au salut: les tuberculeux aux $19 \mathrm{e}$ et $20 \mathrm{e}$ siècles. Paris: Aubier, 1989.

KESSELRING, Thomas. O conceito de natureza na história do pensamento ocidental. Episteme, Porto Alegre, n.11, p.153-172, jul./dez. 2000.

LAZZAROTTI FILHO, Ari et al. O termo práticas corporais na literatura científica brasileira e sua repercussão no campo da educação física. Movimento. Porto Alegre, v. 16, n. 1, p. 11-29, jan/ mar 2010.

LENOBLE, Robert. Histoire de l'idée de Nature. Paris: Albin Michel, 1969.

LIMA, Nísia Trindade; HOCHMAN, Gilberto. Pouca saúde e muita saúva: sanitarismo, interpretações do país e ciências sociais. In: HOCHMAN, Gilberto; ARMUS, Diego (Org.). Cuidar, controlar, curar: ensaios históricos sobre saúde e doenças na América Latina e Caribe. Rio de Janeiro: Fiocruz, 2004. P. 493-533.

LEONTIEV, Alexander; LURIA, Alexis; VIGOTSKII, Lev. Linguagem, desenvolvimento e aprendizagem. São Paulo: Ícone, 1988.

MATSUMOTO, Marina Hisa. 0 ensino-aprendizado do gesto na aula de educação física. 2009. Dissertação (Mestrado em Educação) - Universidade Estadual de Campinas, Campinas, 2009. Disponível em: <http://libdigi.unicamp.br>. Acesso em: 20 out.2014. 
PIKE, Frederick. Natureza e cultura: América Latina, mitos e estereótipos nos Estados Unidos nas décadas de 20 e 30. Projeto História, São Paulo, n. 23, p. 1-503, nov. 2001.

RAUCH, André. Vacances en France: de 1830 à nos jours. Paris: Hachette Littératures, 2001.

RIANT, Aimé. Surmenage intellectuel et les exercices physiques. Paris: Bailliere, 1889.

RIKLI, Arnold. Médecine naturelle et bains de soleil. Lausanne: Bridel, 1905.

SANT'ANNA, Denise Bernuzzi de. Políticas do corpo. São Paulo: Estação Liberdade, 1995.

SILVA, Ana Márcia. Elementos para compreender a modernidade do corpo numa sociedade racional. Cadernos Cedes, Campinas, v.19, n. 48, p. 7-29, ago. 1999.

SILVA, Ana Márcia. A natureza da physis humana: indicadores para o estudo da corporeidade. In: SOARES, Carmen Lucia (Org.). Corpo e história. Campinas: Autores Associados, 2001. p. 25-41.

SILVA, Ana Márcia. Das relações estéticas com a natureza. Revista Brasileira de Ciências do Esporte, Campinas, v. 28, n. 3, p. 141-155, maio 2007.

SILVA, Paula Cristina da Costa. Reflexões e propostas para o ensino-aprendizado da capoeira nas aulas de educação física. 2009. Tese (Doutorado em Educação) - Universidade Estadual de Campinas, Campinas, 2009. Disponível em: <http://libdigi.unicamp.br>. Acesso em: 20 out. 2014.

SIROST, Olivier (Org.). La vie au grand air: aventures du corps et évasions vers la nature. Nancy: Presses Universitaires, 2009.

SOARES, Carmen Lúcia. Educação do corpo. In: GONZÁLEZ, Fernando Jaime;

FENSTERSEIFER, Paulo Evaldo. (Org.). Dicionário crítico de educação física. 3. ed. ljuí: Unijuí, 2014. p. 219-225.

SOARES, Carmen Lúcia (Org.). Corpo e história. Campinas: Autores Associados, 2001.

SOARES, Carmen Lúcia. Imagens da educação no corpo: estudo a partir da ginástica francesa no século XIX. Campinas: Autores Associados, 1998.

SOARES, Carmen Lúcia. Educação física escolar: conhecimento e especificidade. Revista Paulista de Educação Física. São Paulo, supl.2, p.6-12, 1996.

SOARES, Carmen Lúcia (Org.). Pesquisa sobre o corpo: ciências humanas e educação. Campinas: Autores Associados, 2007.

THOMAS, Keith. 0 homem e o mundo natural: mudanças de atitude em relação às plantas e aos animais, 1500-1800. São Paulo: Companhia das Letras, 1988.

VILLARET, Sylvain. Naturisme et éducation corporelle: des projets réformistes aux prises en compte politiques et éducatives (XIXe - milieu du XXe siècles). Paris: L'harmattan, 2005.

WILLIAMS, Raymond. 0 campo e a cidade: na história e na literatura. São Paulo: Companhia das Letras, 2011.

Apoio: Fundação de Amparo à Pesquisa do Estado de São Paulo (FAPESP); Coordenação de Aperfeiçoamento de Pessoal de Nível Superior (Capes). Processo nº. 2014/11153-3. 